\title{
Núcleos de Prática e Assistência Jurídica (NPAJ) de Instituições de Ensino Superior (IES): Instrumento de cidadania e acesso à justiça
}

\section{Practice and Legal Assistance Centers (NPAJ) of Higher Education Institutions (IES): Instrument of citizenship and access to justice}

\author{
Wilson Pereira de Assis ${ }^{1 *}$, Bruno Smolarek Dias ${ }^{1}$
}

\section{RESUMO}

Neste artigo discorro sobre o surgimento, as atribuições, funções - sociais e pedagógicas, além das atuações dos Núcleos de Prática e Assistência Jurídica das Instituições de Ensino Superior. Falo sobre a importância dos NPAJ's para o acadêmico, para a sociedade, para a Defensoria Pública, para o Poder Judiciário e para o Estado. Igualmente, discorro e defendo que os NPAJ's são instrumentos de Cidadania e de Acesso à Justiça, vez que desempenham fundamental papel perante o mundo acadêmico e para a sociedade como um todo, especialmente a sociedade carente.

Palavras-Chave: Núcleos de Prática e Assistência Jurídica; Instituições de Ensino Superior; Instrumento; Cidadania e acesso à justiça.

\section{ABSTRACT}

This article discusses the emergence, attributions, social and pedagogical functions, in addition to the role of the Practice and Legal Assistance Centers of Higher Education Institutions. In addition to talking about the importance of these Centers to academics, society, the Public Defender, the Judiciary and the State. Furthermore, it discusses and defends that these Centers are instruments of citizenship and access to justice, as they play a fundamental role in the academic world and for society, especially the most needy.

Keywords: Practice and Legal Assistance Centers, Higher Education Institutions. Citizenship. Access to justice.

\section{INTRODUÇÃO}

Os Núcleos de Prática Jurídica, também conhecidos como Núcleos de Prática e Assistência Jurídica, Escritórios Modelos e Escritórios de Prática Jurídica das Faculdades de Direito, vinculados às Instituições de Ensino Superior à que pertencem, prestam importante papel pedagógico e social.

\footnotetext{
${ }^{1}$ Universidade Paranaense - UNIPAR - campus Umuarama (PR).

*E-mail: wilson.assis@edu.unipar.br
} 
Possuem características pedagógicas, pois proporcionam aprendizado aos seus alunos por meio do estágio obrigatório supervisionado, e sociais por prestarem assistência jurídica à sociedade, em especial à parcela da sociedade economicamente hipossuficiente.

Quanto às assistências, representam-se por diversas formas, entre elas as orientações jurídicas prestadas, as tentativas de conciliações realizadas, as próprias conciliações realizadas, os acordos extrajudiciais realizados, elaboração de contratos, entre outros, evidenciam formas de acesso à justiça aos hipossuficientes economicamente.

Frisa-se que o acesso à justiça, por positivado em nossa Carta Maior (art. $5^{\circ}$, XXXV), trata-se de direito fundamental, competindo ao Estado efetivar a aplicação desse direito. Daí a importância dos Núcleos de Prática e Assistência Jurídica para a efetivação desse direito, já que, como dito, entre outros argumentos, ajudam a desafogar a Defensoria Pública (DP) e contribuem diretamente com o Estado.

É fato que muitos confundem esses Núcleos com a própria Defensoria Pública, chegando a pensar que os NPAJ's são extensões das DP's, informação que observei em meus aproximadamente 09 (nove) anos atuando como professor-orientador junto a um dos NPAJ's existentes na cidade onde resido, Dourados-MS.

Certo de que são mais de 250 acadêmicos por semestre realizando o estágio obrigatório supervisionado, não sendo incomum proceder com mais de 3.000 (três mil) atendimentos novos por ano, considerando o período anterior à pandemia decorrente do COVI-19.

Destaca-se que os atendimentos que não findam com a orientação jurídica inicialmente prestada levam ao agendamento de um retorno, quando a parte que procurou atendimento, conhecido como assistido, comparece nesse juntamente com a parte contrária, caso necessário, para a tentativa de conciliação.

Pactuada a conciliação, será agendada nova data para que as partes possam assinar os documentos pertinentes. Não havendo conciliação, se assim o assistido preferir, o caso será judicializado. Em que pese isso, é oportuno informar que, por óbvio, cada NPAJ tem autonomia para estabelecer seu campo e forma de atuação. 


\section{NÚCLEOS DE PRÁTICA E ASSISTÊNCIA JURÍDICA DE INSTITUIÇÕES DE ENSINO SUPERIOR (IES)}

Embora nem todos os Núcleos das Instituições de Ensino Superior prestem Assistência Jurídica, meu objetivo com o presente trabalho é discorrer acerca da importância do papel social desenvolvido pelos NPAJ's que prestam assistência jurídica, retratadas pelas diversas formas de atender aos interesses dos assistidos, seja judicial ou extrajudicial.

No entanto, antes de falar sobre os Núcleos propriamente ditos, lembro de que os dois primeiros Cursos de Direito no Brasil foram instituídos em 11 de agosto de 1827; um na cidade de São Paulo (SP) e outro em Olinda (PE), porém inexistia vinculação entre a teoria e a prática. Esta, por sua vez, somente foi incluída na grade curricular dos cursos de Direito em 1972, com caráter e natureza disciplinar e sob a forma de estágio supervisionado, conforme o regramento da Resolução n. 3 do Conselho Federal de Educação.

Posteriormente, já em 1994, o Ministério da Educação, por meio da Portaria 1.886, inseriu os Núcleos de Prática Jurídica nos cursos de Direito, fixando as diretrizes curriculares e o conteúdo mínimo do Curso Jurídico, passando a ser denominada de prática jurídica.

Em 2004, o Conselho Nacional de Educação - CNE, por meio da Resolução n ${ }^{\circ}$ 9, acabou por instituir as Diretrizes Curriculares Nacional do Curso de Graduação em Direito. Atualmente, a Resolução $\mathrm{n}^{\circ}$ 5, de 2020, do mesmo Conselho, estabelece as Diretrizes Curriculares Nacional do Curso de Graduação em Direito.

É certo que, com a prática jurídica decorrente do estágio obrigatório supervisionado, os acadêmicos desenvolvem atividade real e, com isso, conseguem visualizar a atuação do advogado, aplicando aos casos concretos todo o conhecimento teórico que aprenderam durante a graduação, o que é de suma importância para a formação profissional do acadêmico-estagiário, não restando dúvidas acerca dessa importância.

Não menos importante de que o aprendizado oferecido aos acadêmicos é o serviço gratuito - incluindo todo material necessário - oferecido e prestado à sociedade carente, $\mathrm{o}$ que ajuda, inclusive, a desafogar a Defensoria Pública e contribui diretamente com o Estado. 
Em que pese isso, vale lembrar de que os serviços prestados pelos Núcleos não ficam limitados às questões processuais, pois oferecem, entre outros serviços, orientações jurídicas e meios alternativos de solução de conflitos, verdadeiro direito fundamental e instrumento de acesso à justiça aos economicamente hipossuficientes, em contribuição direta para o Estado, responsável direto pela efetivação da aplicação desse direito fundamental.

Ainda, embora a doutrina não aborde o tema na mesma proporção da importância que esses Núcleos representam, é possível identificar três modelos de assistência jurídica, os quais Hudler e Furtado (2009) denominam como modelo privado, modelo público e modelo misto, que assim definiram:

2. Dos modelos de assistência jurídica

Há três modelos de assistência jurídica reconhecidos pela doutrina clássica[1]. Por fins didáticos e para adaptá-los à realidade brasileira, chamaremos de: modelo privado; público e misto, esmiuçados a seguir. 2.1 Modelo Privado

No Brasil, estão presentes os advogados que exercem a profissão sem nada cobrar do usuário de seus serviços, forma esta de advocacia voluntária e não remunerada conhecida por "Advocacia Pro Bono"[2]; por outro lado, também existem aqueles causídicos que recebem uma contraprestação por parte do Estado[3], mais conhecida por "Advocacia Dativa".

2.2 Modelo Público

A Constituição Federal de 1988 trouxe importante inovação no tocante ao modelo público no País. Em primeiro lugar porque trouxe um novo paradigma de atendimento, mais abrangente e emancipatório que o anterior, representado pela expressão "assistência jurídica integral e gratuita"; em segundo, porque previu expressamente uma instituição estatal específica encarregada de promover tal finalidade[4]. De fato, houve uma evolução na assistência jurídica a grupos vulneráveis, na medida em que demandas individuais ou coletivas tradicionalmente negligenciadas passaram a ser juridicamente exigidas e institucionalizadas. Ou seja, tais demandas passaram a ser promovidas por meio do trabalho de funcionários públicos capacitados e especializados. A despeito de ser o modelo que vigora no ordenamento jurídico brasileiro[5], não se pode olvidar que possui críticas, das quais destacamos a necessidade de alto investimento pelo Estado e a real dificuldade em dar tratamento individualizado de maior qualidade, visto que há poucos recursos e uma demanda inesgotável pelo elevado número de usuários.

2.3 Modelo Misto

Tanto o Modelo Público quanto o Modelo Privado têm a função precípua de garantir o Acesso à Justiça; todavia, os usuários não podem depender exclusivamente da caridade de Advogados Voluntários, nem da disponibilidade financeira do Estado para arcar com os Advogados Dativos, tampouco de um crescimento milagroso por parte da Defensoria Pública. Vale dizer, sozinhos tornam-se inegavelmente insuficientes, de modo que, na prática, adota-se um modelo misto, de coexistência das modalidades, visando ao atendimento mínimo de 
demandas que um país com tamanha desigualdade social como o Brasil lhe impõe.

Resumindo, o modelo privado refere-se à advocacia voluntária, podendo ser pro bono, não remunerada; ou dativa, remunerada pelo Estado. O modelo público trata-se do serviço jurídico gratuito prestado pelo Estado, via de regra pela Defensoria Pública; já o modelo misto de assistência jurídica seria o retratado pelos Núcleos de Prática e Assistência Jurídica das Instituições de Ensino Superior Privadas, isso, pois, os professores-orientadores que atuam nesses Núcleos são remunerados pelas respectivas Instituições as quais estão vinculados, sem qualquer ônus para o Estado ou àqueles que se utilizam do referido serviço, o assistido.

Todos esses modelos de assistência jurídica gratuita possuem papel de tamanha relevância social. Entretanto, a Defensoria Pública, por possuir elevada demanda e ser a única Instituição voltada exclusivamente para atender juridicamente pessoas carentes, há muito se encontra abarrotada de serviço, o que, somado à falta de recursos humanos, deixa esse acesso à justiça limitado.

Como auxílio, embora não seja a finalidade exclusiva dos Núcleos de Práticas e Assistência Jurídica, é fato inegável de que esses NPAJ's possuem papel fundamental para que o acesso à justiça das pessoas carentes não encontre obste ao limitado atendimento suportado pela Defensoria Pública.

Ressalta-se que esse atendimento não é limitado por conta da atuação dos Defensores Públicos que, indiscutivelmente, são extremamente qualificados para a função desempenhada, mas, como dito, pela falta de recursos humanos e, também, estruturais.

\section{NÚCLEOS DE PRÁTICA E ASSISTÊNCIA JURÍDICA DE INSTITUIÇÕES DE ENSINO SUPERIOR COMO INSTRUMENTO DE CIDADANIA}

No tópico anterior discorremos sobre os NPAJ das IES, abordando, entre outros assuntos e de uma forma singela, acerca da criação dos cursos de Direito, a criação dos NPAJ's e sobre a importância do serviço oferecido aos acadêmicos de Direito que realizam o estágio obrigatório supervisionado e sobre a importância do serviço gratuito oferecido à população carente. 
É fato que esses Núcleos desempenham papel fundamental para o acadêmico de Direito que está realizando o estágio obrigatório supervisionado, já que é o local onde o acadêmico colocará em prática todo o conhecimento teórico adquirido ao longo do curso. Além disso, o acadêmico participará de toda dinâmica que entornam um caso concreto, experiência fundamental para o futuro operador do Direito.

Para tanto, o estagiário deverá ouvir pacientemente o assistido, precisará identificar o caso e a respectiva solução, se houver. Nem sempre os estagiários possuem essas habilidades quando iniciam o estágio obrigatório, o que não é nenhum problema, uma vez que o próprio estágio obrigatório propicia o desenvolvimento de tais habilidades.

Além dessa oportunidade e experiência de vida oferecida pelos NPAJ's aos acadêmicos, e não menos importante, os Núcleos também oferecem à população economicamente carente a oportunidade de praticarem o exercício de cidadania, o que ocorre no exato momento em que se busca assistência dos NPAJ's, contudo, essa assistência em nada se confunde com assistencialismo, o que indiscutivelmente corrobora a ideia que os NPAJ's são instrumentos para o exercício da cidadania. Em sentido análogo, Colombari e Cunha afirmaram:

Assim, os referidos órgãos são para os alunos o elo de ligação (SIC) entre a teoria e a prática, e para a população uma forma de verem realizada a justiça e respeitados seus direitos. Todavia, são muito mais que isto, representam uma forma de promover a emancipação social, a efetividade dos direitos humanos e de promover a cidadania.

Acerca do conceito de cidadania, Silva o definiu:

O significado histórico do termo cidadania torna-se muito elucidativo se o objetivo for compreender o tratamento distinto que o Estado confere aos diferentes sujeitos de direito que compõem a sociedade ocidental. Na Grécia antiga a expressão cidadão indicava apenas o membro ativo da sociedade política, aquele a quem se deferia o direito de participar das decisões políticas. É o homem livre, ou seja, o "animal político" a que fala Aristóteles. Igualmente, na civitas romanas, o cidadão diferenciava-se do estrangeiro e do escravo por ter direito de tomar parte no culto da cidade, o que demonstra o papel fundamental da religião como fonte do poder político. Nos tempos atuais, apesar da aparente dissolução da aliança entre a Igreja e o Estado, o direito ainda se mostra ritualista, mantendo as mesmas características do direito romano, o que é perceptível na excessiva "processualização" do fenômeno jurídico e na ênfase positivista que é adotada modernamente, a qual concebe o direito emanado pelo poder legislativo estatal como única forma adequada e inquestionável de manter a ordem social. $\mathrm{O}$ status de cidadão, entretanto, no discurso legal, estendeu-se a todos os indivíduos, como reza a nossa Constituição Federal nos seus arts. $1^{\circ}$., II; $5^{\circ}$., LXXI; 22, XIII; 68, par. $1^{\circ}$., II. Assim, os direitos políticos e civis deveriam ser inerentes à condição de ser humano e, portanto, todos 
deveriam ter igual acesso aos meios jurisdicionais de garantia desses direitos, seja por meio da assistência judiciária ou da assessoria jurídica. A Carta Magna é aberta elegendo como um de seus princípios fundamentais a cidadania. $\mathrm{O}$ vocábulo padece com a falta de riqueza conceitual como é tratado. Comum é vê-lo limitado à titularidade ativa, isto é, ao poder de votar e, assim, interferir nas decisões políticas e na vida institucional do país[10]. Uma abordagem tacanha da definição da cidadania dentro de um ordenamento jurídico, obriga-se a ampliar seus horizontes quando fica translúcida a noção de que a igualdade entre os seres humanos não é obra divina, mas uma construção do homem. Tornamo-nos iguais quando, membros de uma coletividade, optamos por uma decisão conjunta que garante a todos igualdade de direitos. Se "povo", conjunto de cidadãos, encerra um conceito que traz a idéia de vínculo, de subordinação, faz-se necessário que para ser sujeito de direito seja cidadão. Essa condição sine qua non é, não apenas um meio, mas um princípio, já que sua ausência acarreta a total privação do direito, deixando o sujeito de ser "semelhante". A cidadania deixa de circunscrever-se aos direitos políticos ativos e passivos, passando a ser o direito básico de ter direitos. É garantia dada àqueles que se vinculam juridicamente ao Estado e almejam serem regidos pelo princípio da legalidade.

Silva concluiu:

Dentro dessa premissa, cidadania como sendo o "direito a ter direitos"[11], volta-se ao texto constitucional para analisar especificamente a questão do acesso à Justiça. Em primeiro plano, primordial é desassociar a idéia de justiça do órgão do Judiciário. $\mathrm{O}$ acesso ao Poder Judiciário é, tão-somente, uma das facetas do acesso à justiça que se desdobra como forma de democratizar o poder. Como ensina o professor Sérgio Sérvulo da Cunha[12] em que está presente a democracia o acesso se traduz em delimitação do poder do Estado. $\mathrm{O}$ Poder Judiciário funciona como instrumento da sociedade ante o Estado. O Poder Judiciário funciona como instrumento da sociedade ante o Estado para garantir os direitos fundamentais e para efetivar o controle do Estado pela sociedade. $\mathrm{O}$ art. $5^{\circ}$., inciso LXXIV da Constituição Federal determina: "o Estado prestará assistência judiciária integral e gratuita aos que comprovarem insuficiência de recurso". Tal preceito traz inserta uma garantia que nada mais é do que uma instituição criada em favor do indivíduo, para que, armado com ela, possa ter ao seu alcance imediato o meio de fazer efetivo o exercício do seu direito subjetivo de ação. Reitera-se, por oportuno, que tal instituição difere do que o grupo entende por assessoria jurídica.

Em complementação, cito Yamamoto (2016) que discorreu sobre o tema cidadania:

Um ordenamento fundado por indivíduos livres é a base dos contratualismos sociais, dos instrumentos racionais de normatização e participação na sociedade, além de ajustes eventuais no caso de uma integração problemática na comunidade. Segundo Cullen (2007), arrolam-se aqui dois grupos de pensadores: os que entendem o pacto social como exercício positivo da autonomia individual (Hobbes, 
Locke, Rousseau, Rawls, Taylor e Habermas), ou como dado negativo, a partir do qual o sujeito busca sua afirmação ou autenticidade (Hegel). Neste conjunto de memória histórica, percebe-se a configuração da semântica moderna da cidadania que compõe parte das ações sociais legitimadas. Tal semântica pode ser verificada nos casos descritos no começo desse texto, na medida em que reiteram a posição absoluta e inflexível do sujeito (cogito), ou mesmo quando sugerem, conforme a lógica atomística que preside a ontologia vigente, a possibilidade de ajuntamentos sociais dominantes, a partir de uma intersubjetividade produzida por supostas substâncias comuns (classe, etnia, religião, ideologia etc.).

[...]

De fato, o investimento educacional é um caminho viável ao exercício ético da cidadania, pois envolve os sujeitos, desde o início da socialização, à convivência com o outro, os diferentes sujeitos que ocupam um mesmo território. No entanto, há também o caminho pragmático sugerido pela redescrição. Sobre isso, salienta-se a dificuldade apresentada pela forma moderna da cidadania, como se viu, fundada na primazia do cogito, cuja irredutibilidade da posição de sujeito tende tanto a reduzir o outro a um alter-ego, quanto a associar a vulnerabilidade à alienação.

$[\ldots]$

A nosso ver, uma práxis comunicacional voltada à cidadania estaria incompleta se apenas viabilizasse o acesso ao conhecimento jurídico e ao saber técnico laboral, excluindo o homem e a cidade humana de sua ação teórica e prática.

$[\ldots]$

A atual Carta Maior, já em seu preâmbulo, revela a preocupação com o exercício dos direitos sociais e individuais, a liberdade, a segurança, o desenvolvimento, a igualdade e a justiça, como valores supremos de uma sociedade fraterna. Ou seja, busca a defesa da cidadania.

Ainda, não passa despercebido que os NPAJ's também vão até o cidadão carente para prestarem serviço jurídico, oferecer-lhe assistência jurídica gratuita e isso se opera mediante as ações sociais em que participam, seja por iniciativa das próprias IES as quais estão vinculados, seja por convite de instituições e/ou órgãos públicos, a exemplo os eventos organizados pelos Municípios, Ministério Público e Escolas. Acerca dos Núcleos Jurídicos da IES, Gimenez (2013) afirmou:

A atuação do Núcleo de Prática Jurídica, formado por professores, advogados e estagiários, orienta-se na perpetuação de uma cultura de paz, destinada a garantir o exercício do poder de cidadania de cada pessoa, a construir uma sociedade livre, justa e solidária, e a promover o bem de todos, sem distinção.

Embora a fala de Gimenes tenha sido direcionada ao Núcleo da Instituição de Ensino em que leciona, não é forçoso concluir de que tais atributos também se aplicam aos demais NPAJ's, encontrando respaldo em Dall (2013), que escreveu: 


\begin{abstract}
Ademais, a essência de um Núcleo de Prática Jurídica é o compromisso com o aluno no sentido primeiro de exercitar os provérbios e brocardos costumeiros da linguagem jurídica debatidas em sua forma escrita, aliada a defesa dos Direitos Fundamentais e Cidadania, na reformulação da organização social, proporcionando direitos aos que não têm direitos e preparando o aluno para o exercício profissional. De que forma? Entre outras coisas, ajudar o aluno a compreender a teoria e fazê-lo transportar para o papel, desmascarando a realidade que se apresenta, usando a própria realidade da Lei como matéria, uma vez que o processo de aprendizagem passa, definitivamente, pela criatividade com que manuseamos assuntos tão sérios como a morte, dor, ética, moral, separação, casamento, etc. Assim sendo, é neste ponto que entra o estágio e a prática jurídica como disciplina; e dentro de uma concepção de educação integral e histórico-crítica tem o seu lugar garantido no currículo do Curso de Direito.
\end{abstract}

Portanto, não piaram dúvidas de que os NPAJ's são instrumentos diretos de acesso ao exercício de cidadania, beneficiando uma parcela considerável de cidadãos que, sem essa ferramenta, ficariam à margem da Justiça.

\title{
3. NÚCLEOS DE PRÁTICA E ASSISTÊNCIA JURÍDICA DE INSTITUIÇÕES DE ENSINO SUPERIOR COMO INSTRUMENTO DE ACESSO À JUSTIÇA
}

Nos tópicos anteriores discorri sobre a criação dos NPAJ's, sobre suas atribuições, forma de atuações e função como instrumento de cidadania. No presente tópico escrevo sobre a atuação dos NPAJ's como forma de possibilitar o acesso à justiça e, para tanto, iniciarei discorrendo sobre acesso a ela.

De antemão, informo que o direito ao acesso à justiça, tradicionalmente falando, está positivado na Convenção Americana de Direitos Humanos, também conhecido como Pacto de San José da Costa Rica, de 22.11.1969, ratificada pelo Brasil em 25.09.1992, que assim reza:

\section{Artigo $8^{\circ}$ - Garantias judiciais}

1. Toda pessoa terá o direito de ser ouvida, com as devidas garantias e dentro de um prazo razoável, por um juiz ou Tribunal competente, independente e imparcial, estabelecido anteriormente por lei, na apuração de qualquer acusação penal formulada contra ela, ou na determinação de seus direitos e obrigações de caráter civil, trabalhista, fiscal ou de qualquer outra natureza.

No Brasil a Constituição Cidadã positivou o acesso à justiça em seu artigo $5^{\circ}$, XXXV, que assim dispõe: Art. $5^{\circ}$ [...] XXXV - a lei não excluirá da apreciação do Poder Judiciário lesão ou ameaça a direito; 
Pois bem, por muito tempo acesso à justiça se confundia com acesso ao Poder Judiciário, o que era, tradicionalmente, sinônimo de acesso ao Poder Judiciário, em verdadeira confusão com o princípio da inafastabilidade do controle jurisdicional, entretanto, o conceito atual de acesso à justiça é ampliado em muito, não se limitando à busca pelo Judiciário.

Atualmente, sem qualquer hesitação, o acesso à justiça está diretamente relacionado com a possibilidade de materialização de um direito, em especial acerca dos direitos humanos.

Nesse contexto, podem ser citados os direitos políticos e sociais que, sem sombra de dúvidas, exteriorizam o exercício da cidadania. Contudo, é indiscutível que o Poder Judiciário exerce elevada importância quanto à efetivação do acesso à justiça, mesmo porque os julgadores não podem se abster das questões sociais, principalmente quanto às questões de políticas públicas.

Inegável que o conceito moderno de aceso à justiça é muito mais amplo de que o conceito tradicional. Deve haver uma interpretação extensiva que vai além do simples acesso ao Poder Judiciário. A palavra “simples”, por mim utilizada, não é empregada no sentido figurado ou pejorativo, pelo contrário, é empregada na frase em seu sentido real para reforçar a ideia de que acesso à justiça não pode ficar limitado ao conceito tradicional.

Quanto à sequência de ideias, Ferreira (2007) esclareceu ao citar Cappelletti e Garth:

Mauro Cappelletti e Bryant Garth deixam bem clara a noção de acesso à Justiça ligada à plena concretização dos direitos individuais e sociais: De fato, o direito ao acesso efetivo tem sido progressivamente reconhecido como sendo de importância capital entre os novos direitos individuais e sociais, uma vez que a titularidade de direitos é destituída de sentido, na ausência de mecanismos para sua efetiva reivindicação. $\mathrm{O}$ acesso à justiça pode, portanto, ser encarado como o requisito fundamental - o mais básico dos direitos humanos - de um sistema jurídico moderno e igualitário que pretenda garantir, e não apenas proclamar os direitos de todos. $22 \mathrm{O}$ 'acesso' não é apenas um direito social fundamental, crescentemente reconhecido; ele é, também, necessariamente, o ponto central da moderna processualística. Seu estudo pressupõe um alargamento e aprofundamento dos objetivos e métodos da moderna ciência jurídica.23 É no Processo judicial, como instrumento do exercício da jurisdição, que se completam os contornos próprios do novo conceito de acesso à Justiça, materializado nos procedimentos necessários à efetiva realização dos direitos em favor do indivíduo ou da coletividade, com observância do tempo razoável e nos limites do devido processo legal. (Grifo meu). 
Ainda, quando se fala em acesso à justiça não podemos deixar de mencionar as cinco ondas desse processo, a primeira está diretamente ligada ao revés pecuniário enfrentado pelas partes. No caso, a falta de recursos pecuniários é indiscutivelmente obste para que o efetivo acesso à justiça se concretize, daí a necessidade da concessão integral da gratuidade da justiça.

A segunda onda, por sua vez, está relacionada à tutela coletiva, direitos difusos que, na maioria das vezes, têm como representante processual da coletividade o Ministério Púbico e a Defensoria Pública. A terceira onda tem relação com a instrumentalidade processual e aos métodos alternativos de soluções de conflitos. No particular, um exemplo clássico trata-se da Lei 9.099/95.

Sobre o tema, Mauro Cappelletti e Bryan Garth (1988, p. 25) escreveram:

[...] essa 'terceira onda' de reforma inclui a advocacia, judicial ou extrajudicial, seja por meio de advogados particulares ou públicos. Ela centra sua atenção no conjunto geral de instituições e mecanismos, pessoas e procedimentos utilizados para processar e mesmo prevenir disputas nas sociedades modernas.

A quarta onda de acesso à justiça pretere questões instrumentais e procedimentais e procura valorizar o justo, dando credibilidade ao profissional do Direito desde a formação acadêmica, valorizando questões éticas; já a quinta onda, conforme a visão de Gomes, objetiva a globalização e direitos humanos e se refere a métodos e meios internacional de direitos humanos, já que, na visão do autor:

Possui fundamento no art. $4^{\circ}$, II, CF, o qual dispõe que a República Federativa do Brasil se rege nas suas relações internacionais pela prevalência dos direitos humanos. Apenas de forma exemplificativa, destaca-se a atuação de instituições perante sistemas internacionais de proteção de direitos humanos. Nota-se, novamente, a Defensoria Pública sendo um instrumento de acesso à justiça - na presente onda referente ao acesso aos sistemas internacionais de proteção dos direitos humanos.

Contudo, e a bem da verdade, para muitos o "simples acesso ao Poder Judiciário" ainda é realidade distante, seja, entre outros motivos, por falta de conhecimento sobre seus direitos, seja por medo de não saber ler, escrever, expressar-se, seja por medo ou "vergonha de expor sua vida" e/ou seja por medo da "toga".

Não é incomum, pelo contrário, é bem comum que pessoas humildes, quando do atendimento no NPAJ, dizerem "Doutor, eu nunca precisei fazer isso", "Eu nunca precisei mexer com a Justiça”, fazendo referência à necessidade de propor ação para resguardar seu direito, então violado ou na iminência de ser infringido, ou seja, esquecendo ou 
mesmo não sabendo de que buscar socorro no NPAJ para tentar resolver extrajudicialmente seu problema, ou mesmo que precise ser judicializada a questão, nada mais é que o exercício de cidadania e, por consequência, acesso à justiça.

Ao longo dos anos em que atuo como professor-orientador de prática e assistência jurídica no Núcleo da IES da qual faço parte, percebi o quanto é comum pessoas tentarem resolver seus problemas pela via extrajudicial por "temerem a toga". Em muitos casos, os assistidos buscam pôr fim aos seus respectivos problemas extrajudicialmente por receio de terem que participar de audiência com juiz togado.

Nalgumas vezes, deixa de existir transação para haver renúncia ao direito, o que, dependendo do caso concreto, não pode ser comungado pelo NPAJ. Entretanto, é certo que resolver o problema sem a necessidade de judicializar a questão é forma de acesso à justiça e contribui, em muito, com o Estado, com o Poder Judiciário, com a sociedade, justamente por ser um processo a menos, entretanto, repita-se, dependendo do caso analisado, não pode ser chancelado.

Embora, em tese, seja mais vantajosa a solução extrajudicial do conflito, o real motivo que leva muitas pessoas humildes a resolverem extrajudicialmente seus problemas deve ser sempre estudado caso a caso para que a renúncia ao direito não se sobreponha ao receio de "enfrentar a toga".

Em que pese isso, não busco aqui falar sobre processo propriamente dito, embora falar de acesso à justiça também é falar de processo, mas darei ênfase às questões mais abstratas relativas a esse acesso, razão pela qual o acesso à justiça é um instrumento para o resguardado de direitos que podem ser materializados judicial ou extrajudicialmente e, a depender do caso concreto analisado, os NPAJ's são instrumentos que propiciam a materialização desse acesso, podendo ou não ser por meio da tutela jurisdicional.

Como o acesso à justiça é direito fundamental, os NPAJ's contribuem e propiciam o exercício e respeito a esses direitos, fundamentais ou não; para parte da doutrina os direitos fundamentais são direitos positivados que visam proteger a dignidade, a igualdade e a liberdade da pessoa humana (CF, art. $\left.5^{\circ}, \mathrm{XXXV}\right)$, razões disso os direitos fundamentais podem ser alterados ao longo do tempo, sempre para garantir mais direitos, nunca para suprimir ou diminuir direitos, em homenagem ao princípio da proibição do retrocesso.

Por conta dessa garantia aos direitos fundamentais, surgem as gerações dos direitos fundamentais; a primeira surgiu na França e pode ser identificada como os 
direitos civis e políticos; os direitos fundamentais de segunda geração são retratados, entre outros, pelo direito à seguridade social e à segurança. Para alguns, o direito ao acesso à justiça seria de segunda geração, já que o Estado deve oferecer meios para que direitos sejam resguardados.

Entretanto, noutro norte, para alguns o direito fundamental não precisa necessariamente estar positivado, nesse sentido, afirmou de Souza (2013):

Concorda-se com os posicionamentos supra mencionados, entretanto entende-se que um direito pode ser considerado fundamental até mesmo se o princípio a que se remete não estiver expressamente previsto na constituição, se decorrerem de princípios consolidados na sociedade a que se dirige. Assim, reputa-se o direito de acesso à justiça como direito fundamental. Considerando o acesso à justiça sob todos os aspectos anteriormente mencionados, o direito de acesso à justiça é imprescindível. $\mathrm{O}$ acesso à justiça sob a perspectiva tradicional, valer dizer, como sinônimo de acesso ao Poder Judiciário, está expressamente positivado como direito fundamental, vez que figura como um dos direitos e deveres individuais e coletivos (art. $5^{\circ}, \mathrm{XXXV}$ ).

Como forma de complementação, cita-se Fernandes (2007) que, em sua dissertação, ao abordar sobre o NPAJ de uma determinada IES, escreveu:

$\mathrm{O}$ acesso à justiça é contextualizado historicamente para se compreender seu amplo significado, o qual motiva a promoção de políticas públicas em prol da sua concretização. Posteriormente, será compreendido no contexto do neoconstitucionalismo e do modelo processual constitucional. A relevância de se assegurar a prerrogativa de conhecer e de reivindicar direitos remete ao direito de assistência jurídica aos vulneráveis e ao papel da Defensoria Pública. A insuficiência em concreto da Defensoria Pública ao cumprimento da sua incumbência implica que se avalie convênio firmado entre ela e os Núcleos de Prática Jurídica. A pesquisa se desenvolveu no NPJ da UNICHRISTUS, e pretende avaliar se o atendimento a vulneráveis prestado pelo corpo discente se dá com consciente intenção de contribuir ao acesso à justiça.

Para fechar este tópico, cita-se Cappelletti e Garth, parafraseados por Vasconcelos (2020):

[...] $\mathrm{O}$ acesso à justiça não é apenas um direito social fundamental, crescentemente reconhecido; ele é, também, necessariamente, o ponto central da moderna processualística. Seu estudo pressupõe um alargamento e aprofundamento dos objetivos e métodos da moderna ciência jurídica.

Evidente, pois, a importância do tema. 


\section{NÚCLEOS DE PRÁTICA E ASSISTÊNCIA JURÍDICA DE INSTITUIÇÕES DE ENSINO SUPERIOR E NEGÓCIOS JURÍDICOS PROCESSUAL}

Dando sequência às atuações dos NPAJ's, chegamos aos negócios jurídicos processual. Para explicar o que é negócio jurídico, trago os esclarecimentos de Reale (2004, p. 208-209), ao dizer que [...] é aquela espécie de ato jurídico que, além de se originar de um ato de vontade, implica a declaração expressa de vontade, instauradora de uma relação entre dois ou mais sujeitos tendo em vista um objetivo protegido pelo ordenamento jurídico.

Sobre negócio processual, Didier Jr (2018, p. 439) diz que é [...] o fato jurídico voluntário, em cujo suporte fático se reconhece ao sujeito o poder de regular, dentro dos limites fixados no próprio ordenamento jurídico, certas situações jurídicas processuais ou alterar o procedimento.

Seguindo esses conceitos e ideias, Câmara (2017, p. 126) define negócio jurídico processual como [...] atos dispositivos, que são aqueles em que as partes livremente regulam suas posições jurídicas no processo, podendo ser unilaterais - renúncia à pretensão -, ou bilaterais, como a transação ou a eleição de foro.

Feito esses esclarecimentos, informo que o atual Código de Processo Civil dá mais autonomia para as partes pactuarem sobre determinado assunto, o que está diretamente ligado aos princípios da autonomia da vontade e da autocomposição, que propiciam a realização de negócios jurídicos processual típicos (previsto na lei) ou atípicos (sem previsão legal e apenas nos processos em que a autocomposição é possível).

Sobre o tema, cita-se Macêdo e Peixoto (2015), que assim ensinam:

Com efeito, quando a celebração do negócio jurídico estiver nos limites do propósito do Estado, que é resolver conflitos e afirmar o ordenamento jurídico, e for desejado e pactuado de forma livre pelos sujeitos parciais, a sua realização, ao contrário de confrontar o devido processo legal, é medida que o afirma e, mais do que isso, leva a um regime de colaboração entre os sujeitos processuais que reforça verdadeira corresponsabilidade no processo.

Não é novidade de que o Código de Processo Civil de 1973 já trazia em seu bojo o instituto negócio jurídico processual típico, a exemplo, a possibilidade de suspensão do processo para que as partes pudessem elaborarem acordo.

Com o atual Código de Processo Civil, a possibilidade de realização de negócio jurídico processual é mais ampla, possibilitando às partes tratarem de diversas matérias, 
sem preterir, todavia, alguns princípios, dentre eles destaco os princípios da boa-fé, da dignidade da pessoa humana e da legalidade.

Respeitados tais princípios, o negócio jurídico processual pode ser realizado previamente, antes do início do processo, no decorrer do processo, ou mesmo após o encerramento processual, sendo possível a realização de negócio processual ainda que não haja previsão expressa na lei sobre o tema, daí por serem denominados de negócio jurídico atípico.

Penso que as informações supracitadas são suficientes para se compreender o instituto negócio jurídico processual, sem, contudo, ter a pretensão de esgotar o tema, não sendo esse o objetivo, mas tão somente explicar esse instituto antes de especificar sobre alguns negócios jurídicos processual aplicados costumeiramente pelos NPAJ's.

Pois bem, é muito comum a renúncia expressa ao prazo recursal nos pedidos de homologação de transação extrajudicial, seja o acordo formulado em petição inicial e/ou em petição intermediária.

Também é comum aos NPAJ's, por meio dos advogados que os representam, pedirem suspensão processual para iniciarem tratativas de eventual acordo; da mesma forma é comum às partes pactuarem datas/prazos para a realização de determinados atos e/ou tratarem acerca de adiamento de audiência.

A prevenção de litígios por meio de solução consensual também é meio de exteriorizar um negócio jurídico processual, importante para as partes e, ainda que indiretamente, para os demais jurisdicionados.

Nota-se, sem qualquer hesitação, que o negócio jurídico processual está diretamente ligado às atuações desenvolvidas pelos Núcleos em evidente observação aos princípios da cooperação, da autocomposição, economia e celeridade processual, assim como autonomia da vontade esculpidos no atual regramento processual cível.

\section{CONSIDERAÇÕES FINAIS}

Os Núcleos de Prática e Assistência Jurídica de Instituições de Ensino Superior prestam, sem qualquer sombra de dúvidas, serviço essencial à população carente e é de muita relevância para o desenvolvimento do acadêmico de Direito que está realizando o estágio obrigatório supervisionado.

Esse acadêmico, além de pôr em prática o conhecimento jurídico adquirido ao longo da graduação, também pratica cidadania ao partilhar seus conhecimentos quando 
da realização do atendimento ao assistido, evidenciando que o conceito atual de cidadania não se limita ao direito de votar e ser votado.

Por conta disso, os NPAJ's correspondem ao elo entre o conhecimento jurídico e as pessoas economicamente carentes, razão pela qual pode-se dizer que esses Núcleos são instrumentos de cidadania por possibilitarem às pessoas sem condições pecuniárias o acesso gratuito a esses conhecimentos e, com isso, conhecerem seus direitos e obrigações.

Também, por isso, os NPAJ's atuam como instrumento de acesso à justiça, sempre a disposição da sociedade economicamente carente, viabilizando o efetivo exercício de um direito social, mesmo quando posto em prática o instituto negócio jurídico processual.

\section{REFERÊNCIAS}

BRASIL. Constituição da República Federativa do Brasil de 1988. Disponível em: http://www.planalto.gov.br/ccivil_03/constituicao/constituicao.htm. Acesso em 29.09.2020.

. Decreto n. 678, de 6 de novembro de 1992. Promulga a Convenção Americana sobre Direitos Humanos (Pacto de São José da Costa Rica), de 22 de novembro de 1969. Disponível em:

http://www.planalto.gov.br/ccivil_03/decreto/d0678.htm. Acesso em 27.09.2020.

CÂMARA, Alexandre Freitas. O novo processo civil brasileiro. 3. ed. São Paulo: Atlas, 2017. p. 126.

CAPPELLETTI, Mauro; GARTH, Bryan. Acesso à Justiça. Tradução Ellen Gracie Northfleet. Porto Alegre: Fabris Editora, 1988, p 25.

COLOMBARI e CUNHA, Graziela e Helvécio Damis de Oliveira. Núcleos de Prática jurídica como instrumentos de acesso à justiça, promoção da cidadania $\mathrm{e}$ transformação da sociedade. Disponível em:

http://www.publicadireito.com.br/artigos/?cod=0d056cb657299810. Acesso em 24.09.2020.

\section{DALL, Glória Regina. A IMPORTANCIA DA RELAÇÃO DO NÚCLEO DE}

PRÁTICA JURÍDICA E OS ALUNOS DE DIREITO: a melhoria da qualidade do ensino prático. Disponível em

http://faef.revista.inf.br/imagens_arquivos/arquivos_destaque/hZKTVy1voGkDhYA_20 13-7-4-16-8-9.pdf. Acesso em 25.09.2020.

DIDIER JR., Fredie. Curso de Direito Processual Civil: parte geral e processo de conhecimento. 20 ed. Salvador: JusPodivm, 2018, p. 439. 
FERNANDES, Giuliano Pimental. Acesso à Justiça e Prática Jurídica: a contribuição do Núcleo de Prática Jurídica. Disponível em file:///C:/Users/samsung/Downloads/607Texto\%20do\%20artigo-2117-1-10-20181114\%20(1).pdf. Acesso em 27.09.2020.

FERREIRA, Francisco Martins. ACESSO À JUSTIÇA E PROCESSO JUDICIAL NA PERSPECTIVA DO ESTADO DEMOCRÁTICO DE DIREITO E À LUZ DOS PRINCÍPIOS CONSTITUCIONAIS DO PROCESSO. Disponível em https://siaiap32.univali.br/seer/index.php/rdp/article/viewFile/7648/4380. Acesso em 13.09.2020.

GIMENEZ, Charlise Colet. Núcleo de Prática Jurídica da URI: Um instrumento de acesso à justiça e efetivação da cidadania. Disponível em:

http://srvapp2s.santoangelo.uri.br/sites/biblioteca/?p=33. Acesso em 25.09.2020.

GOMES, Marcos Vinícius Manso Lopes. Defensoria Pública e as Ondas de Acesso à Justiça. Disponível em https://www.estrategiaconcursos.com.br/blog/defensoriapublica-e-as-ondas-de-acesso-a-justica/. Acesso em 18.11.2020.

HUDLER e FURTADO, Daniel Jacomelli e Marcio Spagnuolo. Núcleos de Prática Jurídica devem ter prerrogativas de defensores públicos. Disponível em: https://www.conjur.com.br/2015-ago-29/nucleos-pratica-juridica-prerrogativasdefensores. Acesso em 20.09.2020.

MACÊDO, Lucas Buril de. PEIXOTO, Ravi de Medeiros. Negócio processual acerca da distribuição do ônus da prova. In: Revista dos Tribunais online. Vol. 241/15 Mar/15.

REALE, Miguel. Lições Preliminares de Direito. 27 Ed. São Paulo: Saraiva, 2004, p. 208-209.

SILVA, Daniele Drummond De Lima e. Papel do núcleo de prática jurídica na efetivação do acesso à justiça e na construção da cidadania. Disponível em https://www.nwadv.com.br/artigos/papel-do-nucleo-de-pratica-juridica-na-efetivacaodo-acesso-a-justica-e-na-construcao-da-cidadania/. Acesso em 24.09.2020.

SOUZA, Vera Leilane Mota Alves de. Breves considerações sobre o acesso à justiça. Disponível em https://jus.com.br/artigos/24200/breves-consideracoes-sobre-o-acesso-ajustica. Acesso em 24.09.2020.

VASCONCELOS, Carlos Eduardo de. O CPC (Lei 13.105/2015) e a Lei de Mediação (13.140/2015) no sistema multiportas de acesso à Justiça. Disponível em: http://genjuridico.com.br/2020/09/30/cpc-mediacao-sistema-multiportas/. Acesso em 17.11.2020. 
YAMAMOTO, Eduardo Yuji. Pensar a cidadania a partir da comunicação. Disponível em https://seer.ufrgs.br/intexto/article/viewFile/65782/42142. Acesso em 30.09.2020.

Recebido em: 01/03/2021

Aprovado em: 20/03/2021

Publicado em: 30/03/2021 